\title{
TupA: A Tungstate Binding Protein in the Periplasm of Desulfovibrio alaskensis G20
}

\author{
Ana Rita Otrelo-Cardoso ${ }^{1, \dagger}$, Rashmi R. Nair ${ }^{1, \dagger}$, Márcia A. S. Correia ${ }^{1}$, Maria G. Rivas ${ }^{1,2, *}$ \\ and Teresa Santos-Silva ${ }^{1, *}$
}

1 Rede de Química e Tecnologia/Centro de Química Fina e Biotecnologia (REQUIMTE/CQFB), Department of Chemistry, Faculdade de Ciências e Tecnologia, Universidade Nova de Lisboa, Caparica 2829-516, Portugal; E-Mails: a.cardoso@ campus.fct.unl.pt (A.R.O.-C.); r.nair@fct.unl.pt (R.R.N.); marcia.correia@fct.unl.pt (M.A.S.C.)

2 Department of Physics, Facultad de Bioquímica y Ciencias Biológicas,

Universidad Nacional del Litoral, Santa Fe 3000, Argentina

$\dagger$ These authors contributed equally to this work.

* Authors to whom correspondence should be addressed;

E-Mails: m.rivas@ fct.unl.pt (M.G.R.); tsss@ @fct.unl.pt (T.S.-S.);

Tel.: +35-121-294-8300 (ext. 10940) (M.G.R.); +54-342-457-5213 (ext. 30) (T.S.-S.);

Fax: +54-342-457-5221 (M.G.R.).

Received: 31 March 2014; in revised form: 29 May 2014 / Accepted: 29 May 2014 /

Published: 2 July 2014

\begin{abstract}
The TupABC system is involved in the cellular uptake of tungsten and belongs to the ABC (ATP binding cassette)-type transporter systems. The TupA component is a periplasmic protein that binds tungstate anions, which are then transported through the membrane by the TupB component using ATP hydrolysis as the energy source (the reaction catalyzed by the ModC component). We report the heterologous expression, purification, determination of affinity binding constants and crystallization of the Desulfovibrio alaskensis G20 TupA. The tupA gene (locus tag Dde_0234) was cloned in the pET46 Enterokinase/Ligation-Independent Cloning (LIC) expression vector, and the construct was used to transform BL21 (DE3) cells. TupA expression and purification were optimized to a final yield of $10 \mathrm{mg}$ of soluble pure protein per liter of culture medium. Native polyacrylamide gel electrophoresis was carried out showing that TupA binds both tungstate and molybdate ions and has no significant interaction with sulfate, phosphate or perchlorate. Quantitative analysis of metal binding by isothermal titration calorimetry was in agreement
\end{abstract}


with these results, but in addition, shows that TupA has higher affinity to tungstate than molybdate. The protein crystallizes in the presence of $30 \%(w / v)$ polyethylene glycol 3350 using the hanging-drop vapor diffusion method. The crystals diffract X-rays beyond $1.4 \AA$ resolution and belong to the $\mathrm{P} 2{ }_{1}$ space group, with cell parameters $a=52.25 \AA, b=42.50 \AA$, $c=54.71 \AA, \beta=95.43^{\circ}$. A molecular replacement solution was found, and the structure is currently under refinement.

Keywords: TupA; tungstate; metal transport; Desulfovibrio; sulfate reducing bacteria; protein-ligand interaction; isothermal titration calorimetry; X-ray crystallography

\section{Introduction}

Molybdenum and tungsten are trace elements used by almost all forms of life. Since Mo and W atoms share several similar chemical characteristics, biological systems have to develop strategies to differentiate one metal from the other and to avoid the incorrect metal insertion in the active site of enzymes [1,2]. These metals enter the cell as soluble oxoanions, $\mathrm{MoO}_{4}{ }^{2-}$ and $\mathrm{WO}_{4}{ }^{2-}$, through specific ATP-binding cassette (ABC) transporter systems. In prokaryotes, these transport systems are divided into three different families: Mod, Wtp and Tup. All of these systems are composed of a periplasmic protein (component A), a transmembrane pore forming protein (component B) and a cytoplasmic protein (component $\mathrm{C}$ ), which hydrolyzes ATP to generate the energy necessary to transport the oxoanion into the cell cytoplasm [2-5]. The genes encoding the three components are organized in an operon ( $m o d / w t p A B C)$ or gene cluster $(t u p A B C)$ regulated by a transcription factor known as ModE in the case of the ModABC operon. Under an excess of molybdate, ModE binds molybdate ions, suffers conformational changes and dimerizes. This metal-protein complex binds to a specific DNA sequence (located upstream of the modABC operon) and downregulates the expression of proteins involved in molybdenum uptake [4,6-8].

Under oxoanion starvation, the component A binds molybdate or tungstate and interacts with the component B to actively transport molybdate or tungstate from the periplasm to the cytoplasm [4]. Therefore, the Mod/Wtp/TupABC transport system and, more specifically, the component A should constitute the first selection gate from which cells should differentiate between Mo and $\mathrm{W}$. The basis for this selectivity is currently unknown. The periplasmic component of the Mod/Tup/WtpABC system differs not only in the primary sequence, but also in the metal affinity and coordination chemistry of the molybdate/tungstate [2,9-16]. Crystal structures of ModA have already been solved, showing a tetrahedral coordination with five conserved amino acids located at a H-bond donating distance from the oxygen atoms of the oxoanions [17-19]. Different from ModA, the tungstate binding protein, WtpA, binds tungstate in a distorted octahedral conformation with two carboxylate oxygens from conserved glutamate (Glu218) and aspartate (Asp160) residues (Pyrococcus furiosus (Pf) numbering), with several examples in the literature [20]. The oxoanion coordination in TupA protein has not yet been reported, but it is known that the TTTS amino acid sequence at the $N$-terminal amino acid sequence is a signature of this type of tungstate transporters. In this motif, the Thr9 and Ser11 (Geobacter sulfurreducens (Gs) numbering) are predicted to be interacting with the oxoanion through 
hydrogen bonds. In addition, a conserved threonine in the $C$-terminal domain, Thr124, is postulated to coordinate the oxoanion through hydrogen bonds [2]. The crystal structure of Gs TupA has been deposited in the Protein Data Bank (PDB code 3LR1) with a $\mathrm{W}^{6+}$ ion close to the TTTS motif. The binding mode of the ion is not clear and needs to be further scrutinized.

Desulfovibrio alaskensis $\mathrm{G} 20(\mathrm{DaG} 20)$ is a sulfate reducing bacterium (SRB) that obtains energy from sulfate reduction and produces sulfide, a highly toxic and corrosive metabolite [21]. SRBs are the main cause responsible for a phenomenon known as microbiologically-influenced corrosion (MIC), with very relevant economic consequences in several industries, including the chemical, paper, power, marine and petroleum industry [22-24]. Molybdate can be used to control the SRB growth mainly by the inhibition of ATP-sulfurylase, a key enzyme in sulfate activation [25-27]. In addition, we have observed that high molybdate concentration in cultures of $D a \mathrm{G} 20$ affect the expression of proteins involved in energy metabolism, ion transport, cell cycle, amino acid, purines, pyrimidines, nucleosides and nucleotides biosynthesis and other cellular mechanisms. Regarding the proteins involved in ion transport, we found that not only the periplasmic protein involved in molybdate transport (ModA), but also the protein involved in tungstate transport (TupA) are downregulated under these stress conditions [28].

Despite the presence of several relevant Mo- and W-containing enzymes in the Desulfovibrio metabolism, there are no reports about molybdate/tungstate transport systems in this organism. Genome analysis shows that it codifies both molybdate and tungstate transporters. The tungstate transport system corresponds to the Tup kind of transporters. Analysis of the primary sequence of the DaG20 TupA contains all of the conserved residues putatively involved in the oxoanion coordination [1] (Figure 1).

Figure 1. Multiple sequence alignment of TupA proteins performed with ClustalW [29]. Dde_0234, Desulfovibrio alaskensis G20; DVU0745, Desulfovibrio vulgaris Hildenborough; Dde_2876, Desulfovibrio salexigens; Cj1540; Campylobacter jejuni strain NCTC 11168; Dde_1778, Desulfovibrio desulfuricans ATCC 27774; GSU2700, Geobacter sulfurreducens. Residues putatively involved in the coordination of tungstate are highlighted in black. Symbols: (*) identity, (:) strongly similar and (.) weakly similar.
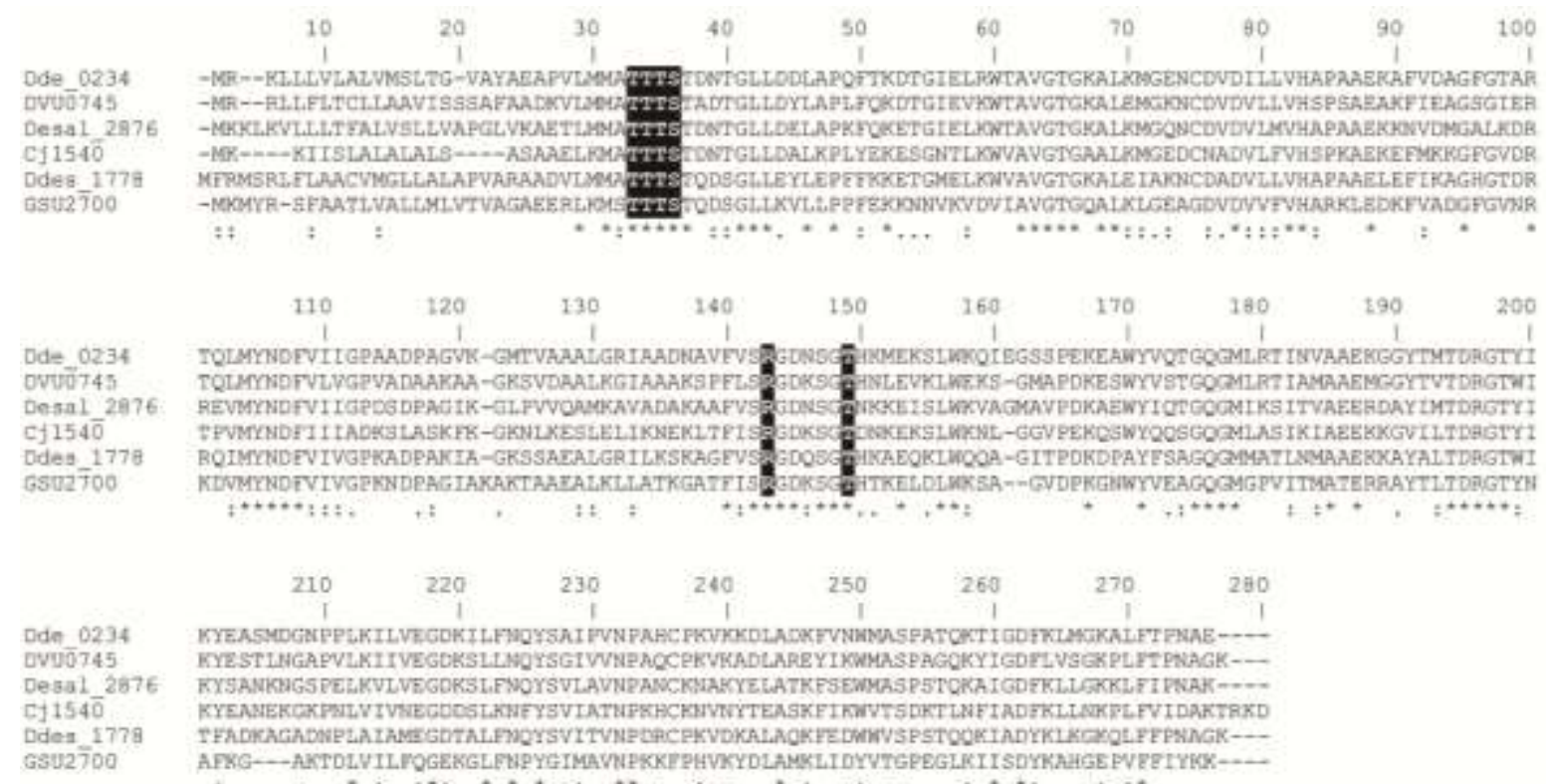
Here, we report the expression, purification, determination of affinity binding constants and crystallization of the DaG20 TupA protein. The high resolution structure (up to $1.4 \AA$ resolution) will provide useful information about the coordination geometry of the oxoanion to the protein. In addition, the expression system and purification protocol described are useful to construct mutants that will make a relevant contribution to the knowledge of the selectivity mechanisms that allow the cell to differentiate between Mo and W.

\section{Results and Discussion}

\subsection{Cloning of tupA Gene and Purification of TupA Protein}

The tupA gene (Dde_0234) was cloned into the pET-46 Ek/LIC vector using the Ek-LIC cloning system (Novagen, Darmstadt, Germany), and the protein was expressed in BL21 (DE3) cells. The expression level of TupA and the ratio TupA/contaminants were evaluated by SDS-PAGE at different induction times ( $3 \mathrm{~h}, 5 \mathrm{~h}$ and overnight), and $3 \mathrm{~h}$ of induction were considered the optimum condition for TupA production in BL21 (DE3) cells. SDS-PAGE showed that TupA is present in both the soluble and insoluble fraction (data not shown). Since the amount of TupA in the soluble fraction was considered enough to perform the studies here described, we proceed to isolate the protein from this fraction. As explained in the Experimental Section, TupA purification protocol includes two steps, an anionic exchange and a size exclusion chromatography. TupA elutes from the anionic exchange resin at approximately $200 \mathrm{mM}$ Tris- $\mathrm{HCl}$ (pH 7.6), which is in agreement with the isoelectric point calculated for the protein (pI 5.69, ProtParam tool [30]). The degree of purity after each purification step was evaluated by SDS-PAGE (Figure 2). According to the protein sequence, the molecular weight of the recombinant protein should be approximately $29 \mathrm{kDa}$. The purification yield was calculated to be approximately $10 \mathrm{mg}$ of soluble protein per liter of cell culture.

Figure 2. SDS-PAGE stained with Coomassie blue of (1) molecular weight markers (Bio-Rad; from top: 100, 75, 50, 37, 25, 20, 15 and $10 \mathrm{kDa}$ ); (2) the soluble protein fraction; (3) the TupA fraction after anionic exchange chromatography; and (4) the TupA fraction after molecular exclusion chromatography (approximately $15 \mu \mathrm{g}$ of pure protein).

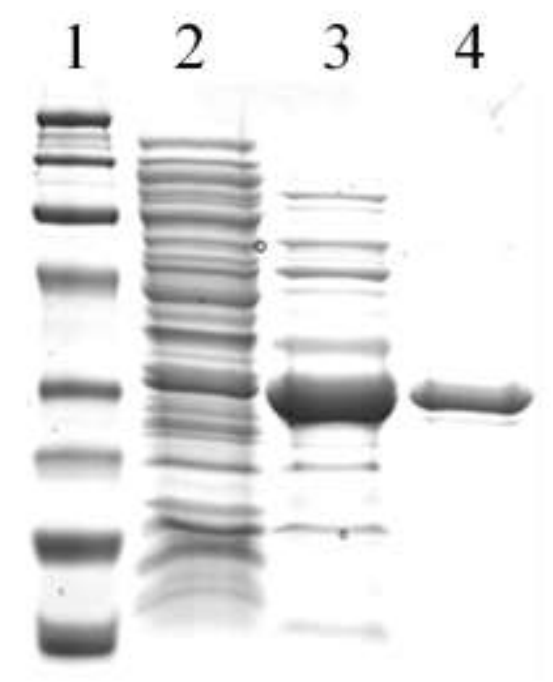




\subsection{UV-Visible Spectrum and Protein Sequence}

The UV-visible spectrum of the as-isolated TupA protein is shown in Figure 3. The maximum observed at $280 \mathrm{~nm}$ is due to the six Tyr residues present in the primary structure, whereas the shoulder at $288 \mathrm{~nm}$ is probably derived from the four Trp residues (Figure 1, Dde_0234).

Figure 3. UV-visible spectrum of as isolated TupA protein $(0.020 \mu \mathrm{M}$ protein in $50 \mathrm{mM}$ Tris-HCl pH 7.6).

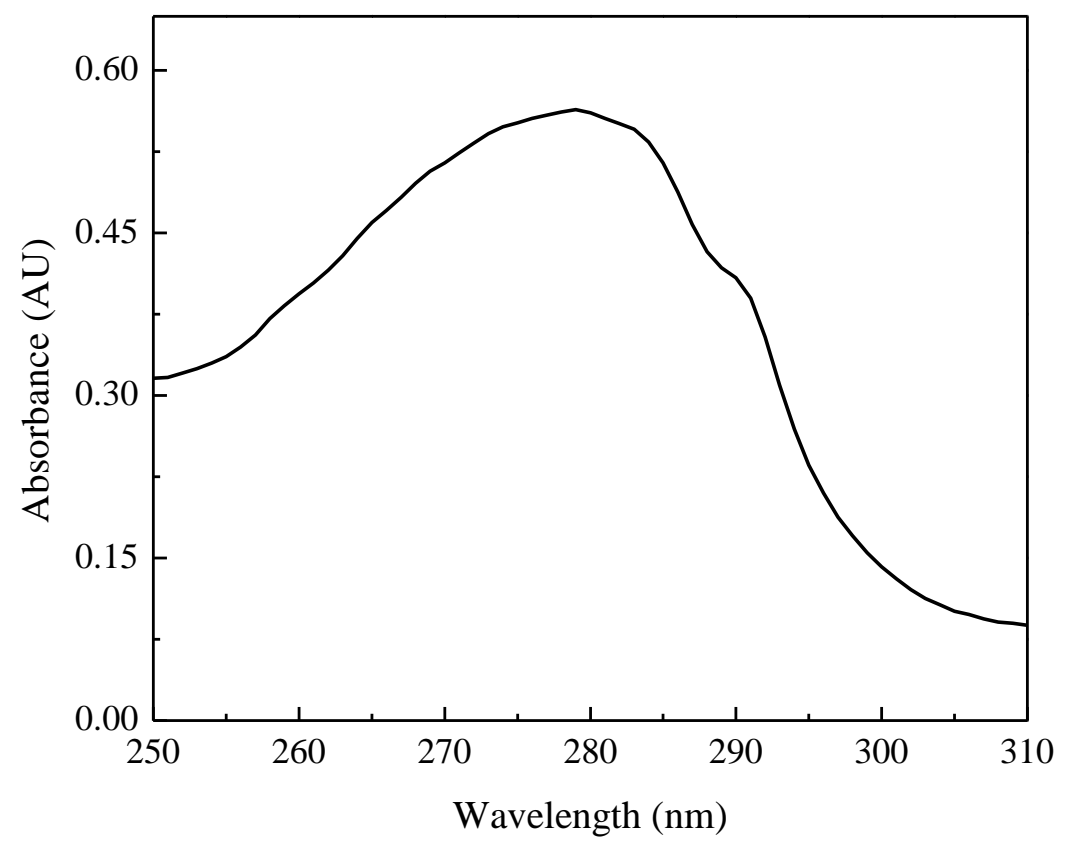

The extinction coefficient of TupA at $280 \mathrm{~nm}\left(29,700 \pm 700 \mathrm{M}^{-1} \cdot \mathrm{cm}^{-1}\right)$ was found to be in good agreement with that deduced from the amino acid sequence of the pure protein $\left(30,440 \mathrm{M}^{-1} \cdot \mathrm{cm}^{-1}\right)$.

Multiple sequence alignment of TupA proteins shows that the DaG20 TupA contains the TTTS motif at the $N$-terminal region, which is the typical signature of this kind of tungstate transporter. The amino acids suggested to form hydrogen bonds with the oxoanion are Thr124, Thr9 and Ser11 (the last two residues from the TTTS motif, G. sulfurreducens numbering). In addition, another conserved and positively charged Arg118 is highly conserved not only in the DaG20 TupA, but also in TupA from different Desulfovibrio species. This residue is proposed as the structural element conferring the high selectivity of the TupA proteins (Figure 1).

\subsection{Metal Binding Assays}

Sequence analysis suggests that $D a \mathrm{G} 20$ TupA is a tungstate-binding protein that is able to bind tungstate and molybdate ions. To test the affinity and specificity of TupA to different anions, native polyacrylamide gel electrophoresis of samples pre-incubated with different oxoanions $\left(\mathrm{MoO}_{4}{ }^{2-}\right.$, $\mathrm{WO}_{4}{ }^{2-}, \mathrm{SO}_{4}{ }^{2-}, \mathrm{PO}_{4}{ }^{3-}$ and $\mathrm{ClO}_{4}{ }^{-}$) was carried out similar to that described in [8]. The samples were submitted to a gel filtration column prior to loading on native polyacrylamide gel in order to separate the unbound ions and to ensure that differences in mobility were only due to the binding of anions to the protein. As seen in Figure 4, TupA showed a significant mobility shift upon binding to tungstate 
and molybdate, but not with the other anions. Both molybdate and tungstate induced similar shifts in the mobility of TupA, and incubation with higher concentrations of anions (100-fold) had no visual impact. Quantitative studies of molybdate and tungstate binding were then performed using isothermal titration calorimetry (ITC).

Figure 4. Ligand-dependent mobility shift assays for TupA protein $(14 \mu \mathrm{M})$ in the presence of different oxoanions (10-fold excess). Lane 1: TupA; Lane 2: TupA $+\mathrm{MoO}_{4}{ }^{2-}$; Lane 3: TupA + $\mathrm{WO}_{4}{ }^{2-}$; Lane 4: TupA $+\mathrm{SO}_{4}{ }^{2-}$; Lane 5: TupA $+\mathrm{PO}_{4}{ }^{3-}$; Lane 6: TupA $+\mathrm{ClO}_{4}^{-}$.

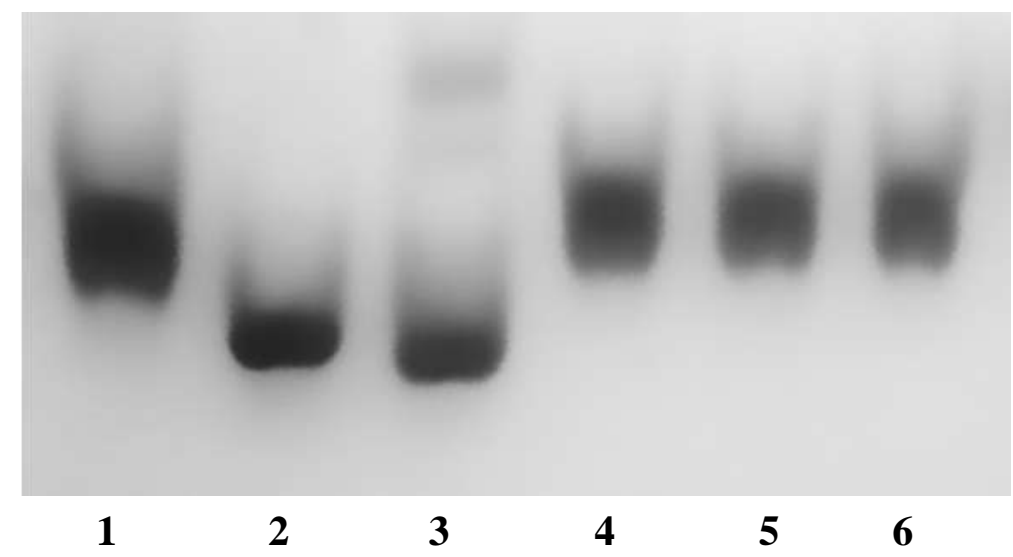

\subsection{Isothermal Titration Calorimetry (ITC)}

ITC has been proven to be a sensitive method to determine affinity constants for tungstate- and molybdate-binding proteins, TupA and ModA, in the nanomolar and subnanomolar ranges $[10,12,16]$. It has the advantage that nearly all interactions give rise to a heat change, which can be monitored with a high-sensitivity calorimeter, and the binding enthalpy $\left(\Delta H_{\mathrm{obs}}\right)$ and dissociation constant can be derived. The observed behavior of TupA is consistent with an exothermic process at this temperature $\left(30{ }^{\circ} \mathrm{C}\right)$, with a single binding site model of binding. However the high nature of these bindings precluded an accurate fit to determine the $K_{\mathrm{D}}$ values. Displacement titrations were done to obtain the correct affinities. The $K_{\mathrm{D}}$ value of a displacement titration in combination with the $K_{\mathrm{D}}$ value for the inhibiting ligand in the absence of a strong binding ligand can be used to calculate the actual $K_{\mathrm{D}}$ for the strong binding ligand (Equation (1; see Section 3.6).

ITC of TupA showed that the protein exothermically binds tungstate and molybdate with a stoichiometry of one mole oxoanion per mole of protein, as deduced from the heat release upon the addition of tungstate or molybdate to the protein solution (Figure 5B). Direct titration of sodium molybdate against TupA produced an exothermic binding isotherm with a $K_{\mathrm{D}}$ value of $6.1 \pm 0.9 \mathrm{nM}$. The value of $\Delta H_{\mathrm{obs}}$ (approximately $6.6 \mathrm{kcal} / \mathrm{mol}$ of injectant) is also significantly less favorable, when compared with the tungstate binding. In contrast, the binding of tungstate to TupA is much more exothermic (Figure 5A; Table 1), with $\Delta H_{\text {obs }}$ being increased to approximately $14 \mathrm{kcal} / \mathrm{mol}$ of injectant (Table 1). The extremely high affinity of the protein for tungstate resulted in a very steep binding curve, which hampers the determination of $K_{\mathrm{D}}$. In order to overcome this problem and to determine a $K_{\mathrm{D}}$ value for tungstate, a binding competition strategy was adopted. A displacement titration of the molybdate-saturated protein with tungstate clearly showed that the protein favors the binding of tungstate, even when the binding site is occupied with a molybdate molecule. The apparent binding 
constant depends on the concentration of free molybdate, which was $0.5 \mathrm{mM}$, and therefore, $K_{\mathrm{D}}$ for tungstate when the protein is saturated with molybdate was determined to be $6.30 \pm 0.02 \mathrm{pM}$ (Figure 5C, Table 1). The displacement titration and the extremely low $K_{\mathrm{D}}$ value for tungstate indicate that the latter should be the physiological substrate for TupA, as expected. The results obtained are in good agreement with those obtained for tungstate binding proteins from Campylobacter jejuni [12] and $P$. furiosus [10] and is approximately 1000 times higher than the $K_{\mathrm{D}}$ value obtained for the E. acidaminophilum TupA [11].

Figure 5. Isothermal titration calorimetry of ligand binding to TupA. TupA $(10 \mu \mathrm{M})$ was titrated with injections of $100 \mu \mathrm{M}$ tungstate (A) and $100 \mu \mathrm{M}$ molybdate (B); (C) Displacement titration of $10 \mu \mathrm{M}$ TupA incubated with $0.5 \mathrm{nM}$ molybdate, with injections of $100 \mu \mathrm{M}$ tungstate. Data were fitted with ORIGIN software. The raw ITC data are shown in the top graphs.
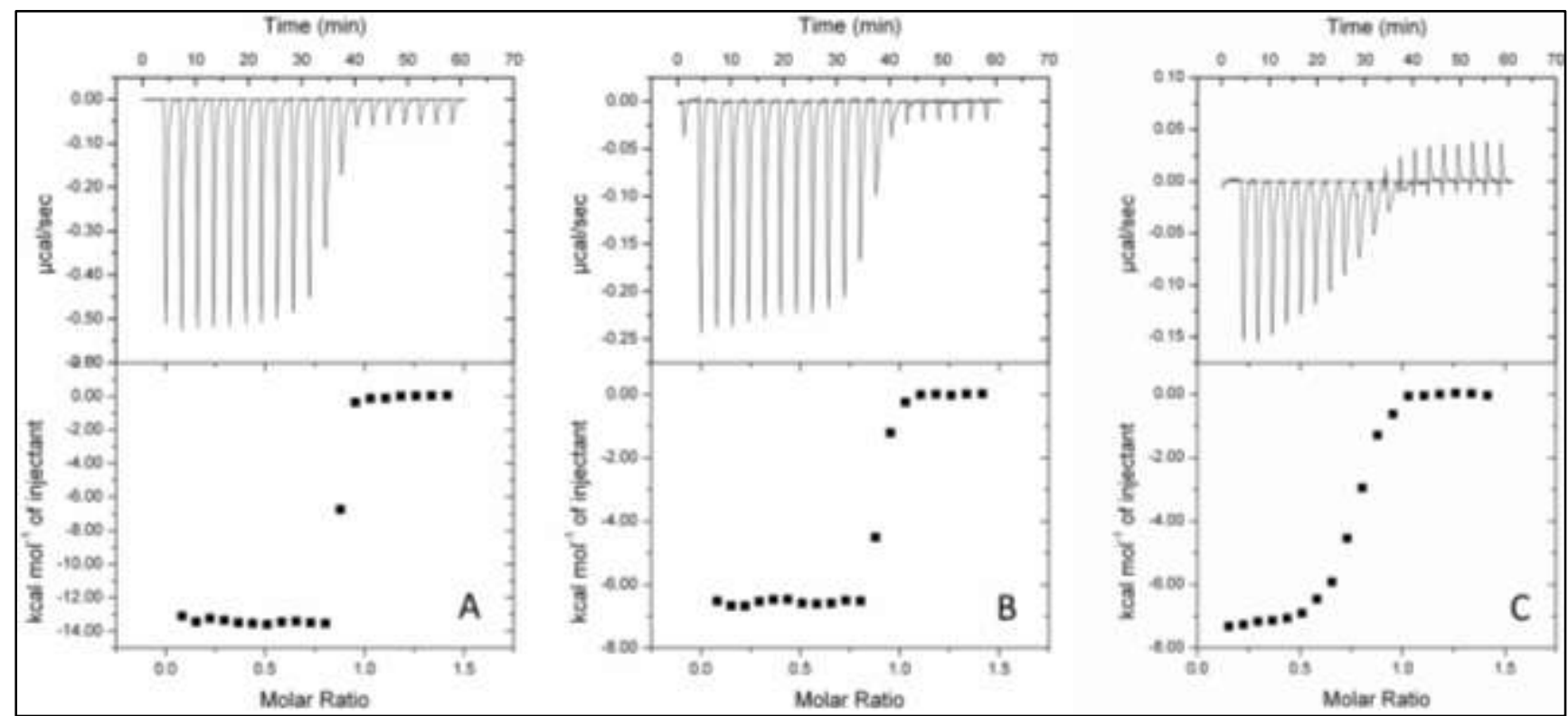

Table 1. Data for the ITC analysis of oxoanion binding to TupA and ModA proteins at $30{ }^{\circ} \mathrm{C}$.

\begin{tabular}{|c|c|c|c|c|c|}
\hline Protein (+Oxyanion) & Ligand & $n$ & $K_{\mathrm{A}}\left(\mathbf{M}^{-1}\right)$ & $K_{\mathrm{D}}(\mathrm{nM})$ & $\Delta H\left(\mathrm{kcal} \cdot \mathrm{mol}^{-1}\right)$ \\
\hline \multirow{2}{*}{ TupA } & $\mathrm{WO}_{4}{ }^{2-}$ & $0.842 \pm 0.001$ & $2 \times 10^{9} \pm 2 \times 10^{9}$ & $0.5 \pm 0.4$ & $-13.500 \pm 0.005$ \\
\hline & $\mathrm{MoO}_{4}{ }^{2-}$ & $0.868 \pm 0.002$ & $16 \times 10^{7} \pm 2 \times 10^{7}$ & $6.1 \pm 0.9$ & $-6.600 \pm 0.003$ \\
\hline TupA $+0.5 \mathrm{mM} \mathrm{MoO}_{4}^{2-}$ & $\mathrm{WO}_{4}{ }^{2-}$ & $0.845 \pm 0.003$ & $1600 \times 10^{8} \pm 6 \times 10^{8}$ & $6.30 \times 10^{-3} \pm 0.02 \times 10^{-3}$ & $-14.60 \pm 0.04$ \\
\hline TupA $+0.5 \mathrm{mM} \mathrm{WO}_{4}{ }^{2-}$ & $\mathrm{MoO}_{4}{ }^{2-}$ & & No & isplacement & \\
\hline
\end{tabular}

In each case $10 \mathrm{mM}$ protein was used for the titrations. $n=$ measured stoichiometry of binding.

\subsection{Crystallization and Data Processing}

To crystallize TupA from $D a \mathrm{G} 20$, several commercial screens were tested in a 96-well plate using the sitting drop/vapor diffusion method. Plate shaped crystals appeared four days after crystallization setup when using a solution of $0.2 \mathrm{M}$ magnesium chloride, 0.1 M HEPES (4-(2-hydroxyethyl) piperazine-1-ethanesulfonic acid) $\mathrm{pH} 7.5$ and $30 \%(w / v)$ polyethylene glycol 3350 as the precipitating agent (Figure 6). 
The scale-up optimization was achieved by varying the protein:precipitant proportion in the crystallization drop, and crystals diffracting up to $1.43 \AA$ resolution were obtained (data collection statistics are presented in Table 2). The crystals belong to the space group $\mathrm{P} 2{ }_{1}$, and the Matthews coefficient calculation $\left(2.09 \AA^{3} \cdot \mathrm{Da}^{-1}\right)$ suggests the presence of one molecule of TupA per asymmetric unit and a solvent content of $40.84 \%$. The $\mathrm{L}$ test for twinning indicates that these correspond to untwined crystals [31].

Figure 6. TupA crystal grown in $0.2 \mathrm{M}$ magnesium chloride, $0.1 \mathrm{M}$ HEPES pH 7.5 and 30\% $(w / v)$ polyethylene glycol 3350 solution. Each unit in the scale bar corresponds to $0.1 \mathrm{~mm}$.

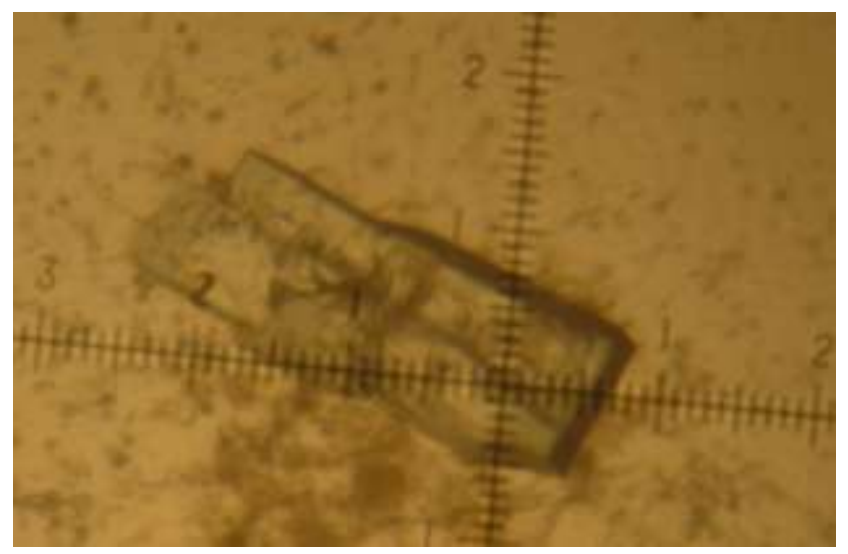

Table 2. Data collection and processing statistics for the TupA crystal. Values in parentheses correspond to the highest resolution shell.

\begin{tabular}{|c|c|}
\hline \multicolumn{2}{|c|}{ Data Collection Parameters } \\
\hline X-ray source & ID23-1 (ESRF, Grenoble) \\
\hline Detector & PILATUS 6M-F \\
\hline Wavelength $(\AA)$ & 0.954 \\
\hline \multicolumn{2}{|c|}{ Processing Statistics } \\
\hline Unit-cell parameters $\left(\AA,^{\circ}\right)$ & $a=52.25 ; b=42.50 ; c=54.71 ; \beta=95.43$ \\
\hline Space group & $\mathrm{P} 12_{1} 1$ \\
\hline Molecules per AU & 1 \\
\hline Matthews coefficient $\left(\AA^{3}, \mathrm{Da}\right)$ & 2.09 \\
\hline Mosaicity $\left(^{\circ}\right)$ & 0.22 \\
\hline Resolution range $(\AA)$ & $42.50-1.43(1.45-1.43)$ \\
\hline$\langle I / \sigma I>$ & $10.3(2.1)$ \\
\hline$R_{\text {merge }}(\%) *$ & $4.1(33.5)$ \\
\hline$R_{\text {pim }}(\%)^{+}$ & $2.7(23.4)$ \\
\hline $\mathrm{R}_{\text {meas }}(\%)^{\S}$ & $5.0(4.1)$ \\
\hline Multiplicity & $3.0(2.8)$ \\
\hline No. of observed reflections & $132,115(6040)$ \\
\hline No. of unique reflections & $43,950(2151)$ \\
\hline Completeness $(\%)$ & $99.1(98.8)$ \\
\hline
\end{tabular}

$* R_{\text {merge }}=\frac{\sum_{h k l} \sum_{i}\left|I_{i}(h k l)-\langle l(h k l)\rangle\right|}{\sum_{h k l} \sum_{i} I_{i}(h k l)} ;{ }^{+} R_{\text {pim }}=\frac{\sum_{h k l}\left[\frac{1}{N-1}\right]^{1 / 2} \sum_{i}\left|I_{i}(h k l)-\langle I(h k l)\rangle\right|}{\sum_{h k l} \sum_{i} I_{i}(h k l)} ;{ }^{\S} R_{\text {meas }}=\frac{\sum_{h k l}\left[\frac{N}{N-1}\right]^{1 / 2} \sum_{i}\left|I_{i}(h k l)-\langle I(h k l)\rangle\right|}{\sum_{h k l} \sum_{i} I_{i}(h k l)}$. 


\subsection{Structure Determination}

To solve the structure of TupA, sequence alignments were performed in order to find the best homologous models that could lead to good initial phases obtained by molecular replacement (MR). The available structures deposited in the PDB, from the three families of transporters ModA, WtpA and TupA, have low sequence identity, but a high degree of three-dimensional homology, with very few structural differences. Structure determination was performed with PHASER [32] using as molecular models: a conserved functionally unknown protein from Vibrio parahaemolyticus RIMD 2210633 (PBD code 3MUQ) and the Gs TupA (PDB code 3LR1). In the first attempts to solve the phase problem, the two homology models were superposed and the non-conserved amino acids were pruned in order to facilitate the rotational and translational searches. Nevertheless, an MR solution could only be obtained when searching for small sections of the protein separately: Section I, from Residues 1 to 81; Section II from Residues 82 to 188; and finally, Section III from Residues 189 to 236. This procedure is commonly used for large, multi-domain or oligomeric proteins, where a high degree of flexibility is expected between the different domains/subunits. In the present case, it suggests that $D a \mathrm{G} 20$ TupA is also a flexible protein that can adopt multiple conformations. The protein crystal structure is currently under refinement, and the details of the putative tungstate/molybdate binding site are going to be inferred.

\section{Experimental Section}

\subsection{Bacterial Strains and Plasmids}

The $D a \mathrm{G} 20$ cells were grown in $100-\mathrm{mL}$ rubber-stropped flasks containing $90 \mathrm{~mL}$ of medium C from Postgate [33] at $37{ }^{\circ} \mathrm{C}$ under anaerobic conditions. The media preparation includes oxygen removal by boiling and bubbling with pure argon for $30 \mathrm{~min}$ and sterilization at $121{ }^{\circ} \mathrm{C}$ at 20 psi for $20 \mathrm{~min}$. The information on the bacteria strain, plasmid and primers used in this study are given in detail in Table 3.

Table 3. Bacterial strains and plasmids used in this study.

\begin{tabular}{|c|c|c|}
\hline Strain/Plasmid/Primer & Properties/Sequence & Source/Reference \\
\hline $\mathrm{DaG} 20$ & $\begin{array}{c}\text { Spontaneously nalidixic acid resistant derivative of } \\
\text { G100A, isolated from the production fluids of offshore } \\
\text { oil fields in Alaska }\end{array}$ & $\begin{array}{l}\text { Feio, M.J. [21], } \\
\text { Hauser, L.J. [34] } \\
\text { and Wall, J.D. [35]. }\end{array}$ \\
\hline pET-46 Ek/LIC vector & E. coli cloning vector plasmid & Novagen \\
\hline NovaBlue GigaSingles cells & $\begin{array}{l}\left.\text { endA1 hsdR17 (rK12- } \mathrm{mK} 12^{+}\right) \text {supE44 thi-1 recAl } \\
\text { gyrA96 relAl lac }\left[\mathrm{F}^{\prime} \mathrm{proA} A^{+} B^{+} \text {lacl }^{q} Z \Delta M 15:: \operatorname{Tn} 10\left(\mathrm{Tc}^{\mathrm{R}}\right)\right]\end{array}$ & Novagen \\
\hline E coli $\mathrm{BL} 21(\mathrm{DE} 3)$ & $\begin{array}{c}\left.F^{-} \text {ompT gal dcm lon hsdSB( } r B^{-} m B^{-}\right) \lambda(D E 3 \\
\text { [lacI lacUV5-T7 gene } 1 \text { ind1 sam7 nin5]) }\end{array}$ & Studier, F.W. [36] \\
\hline TupA_LIC_Fwd (sense) & $\begin{array}{c}\text { GACGACGACAAGATGCTGGAAGTTCTGTTCCA } \\
\text { GGGGCCCGAAGCACCGGTTCTTATG }\end{array}$ & This work \\
\hline TupA_LIC_Rev (antisense) & GAGGAGAAGCCCGGTTATTCGGCGTTGGGGGT & This work \\
\hline
\end{tabular}




\subsection{Cloning of tupA Gene and Protein Expression Optimization}

The tupA gene (locus tag Dde_0234) was amplified from DaG20 cells using the primers included in Table 3. DNA template was obtained from $D a \mathrm{G} 20$ cells grown until the stationary phase. Briefly, $1 \mathrm{~mL}$ of the cell culture was centrifuged, and the pellet was resuspended in $30 \mu \mathrm{L}$ of sterile deionized water. This suspension was boiled for $5 \mathrm{~min}$ in a boiling water bath and then centrifuged at 14,000 rpm for $2 \mathrm{~min}$. A volume of $2 \mu \mathrm{L}$ of the supernatant was used as the DNA template. The amplification reaction was carried out using FideliTaq ${ }^{\mathrm{TM}}$ DNA polymerase (Expand High Fidelity PCR System, Roche, Manneheim, Germany), following the manufacturer's instructions. The PCR program was as follows: initial denaturation step for $2 \mathrm{~min}$ at $92{ }^{\circ} \mathrm{C}$ followed by 25 cycles of $92{ }^{\circ} \mathrm{C}$ for $30 \mathrm{~s}, 55^{\circ} \mathrm{C}$ for $30 \mathrm{~s}$ and $68{ }^{\circ} \mathrm{C}$ for $1 \mathrm{~min}$ and final extension of $68{ }^{\circ} \mathrm{C}$ for $5 \mathrm{~min}$. The amplicon (approximately $800 \mathrm{bp}$ ) was purified using the QIAquick extraction kit (Qiagen, Venlo, Netherlands) and quantified by the UV-visible spectrum. The insert (240 ng) was cloned in the pET-46 Ek-LIC vector using the LIC cloning system (Novagen), following the manufacturer's instructions. NovaBlue GigaSingles competent cells (Novagen) were transformed with the pET46-tupA expression vector, and the plasmid was isolated from a single colony using the NZY-Tech Miniprep kit (NZY-Tech, Lisbon, Portugal). The recombinant plasmids were sequenced using an ABI3700 DNA analyzer (Perkin/Elmer/Applied Biosystems, Stabvida, Caparica, Portugal). The sequences were analyzed and aligned using the online tool, BLASTp [37], and ClustalW [38].

BL21 (DE3) cells were transformed with the pET46-tupA expression vector, and the protein production was evaluated at different concentrations of IPTG $(0,0.2,0.5$ and $1.0 \mathrm{mM})$ and the induction time ( $3 \mathrm{~h}, 5 \mathrm{~h}$ and overnight). To test whether TupA is produced as a soluble protein, the BugBuster reagent (Novagen) was used as per the protocol.

\subsection{Protein Expression and Purification}

E. coli BL21 (DE3) cells containing the pET46-tupA were cultured in sterile Luria-Bertani medium containing ampicillin $(100 \mu \mathrm{g} / \mathrm{mL})$ at $220 \mathrm{rpm}$ and $37^{\circ} \mathrm{C}$. When the $\mathrm{OD}_{600}$ reached $0.4 \mathrm{AU}$, cells were induced with $0.1 \mathrm{mM}$ IPTG during $3 \mathrm{~h}$ at room temperature. The cells were collected by centrifugation at $7000 \mathrm{rpm}$ for $15 \mathrm{~min}$, washed in $5 \mathrm{mM}$ Tris-HCl buffer, centrifuged at $7000 \mathrm{rpm}$ for $15 \mathrm{~min}$ and resuspended again in $5 \mathrm{mM}$ Tris- $\mathrm{HCl}$ buffer containing DNase $(5 \mu \mathrm{g} / \mathrm{mL})$ at a ratio of $2 \mathrm{~g}$ cells $/ \mathrm{mL}$. The cell suspension was freeze and thawed thrice before disrupting the cells on a French press cell at $150 \mathrm{psi}$. The crude extract was centrifuged at $9000 \mathrm{rpm}$ for $30 \mathrm{~min}$, ultracentrifuged using a Beckman Coulter Optima $^{\mathrm{TM}}$ LE-80K ultracentrifuge (Beckman Coulter, Inc., Fullerton, CA, USA) at 45,000× $g$ for $45 \mathrm{~min}$ and the soluble fraction was filtered through a $0.45 \mu \mathrm{m}$ membrane. Although the pET-46 Ek/LIC expression vector encoded a six-histidine tag at the $N$-terminal sequence, attempts to purify TupA using immobilized-metal affinity chromatography (IMAC) failed to bind the protein to the resin. Hence, the strategy to purify TupA was changed to the protocol described as follows. The first purification step involved the loading of the soluble extract into a DEAE Sepharose Fast Flow (GE Healthcare Bio-Sciences AB, Uppsala, Sweden) resin equilibrated with 3 column volumes (CV) of $5 \mathrm{mM}$ Tris- $\mathrm{HCl}$ (equilibration buffer). After protein loading, the resin was washed with equilibration buffer to remove the unbound proteins, and TupA was eluted using a gradient from 
5 to $500 \mathrm{mM}$ Tris- $\mathrm{HCl}$ buffer in $8 \mathrm{CV}$. The protein fractions collected were analyzed by $12 \%$ SDS-PAGE stained using Coomassie blue. The fractions containing TupA were concentrated and loaded onto a Superdex 75 HR10/300 GL column (GE Healthcare Bio-Sciences AB, Uppsala, Sweden) equilibrated with $50 \mathrm{mM}$ potassium phosphate buffer containing $150 \mathrm{mM} \mathrm{NaCl}$. The fraction containing the pure protein was pooled, concentrated and stored at $-80{ }^{\circ} \mathrm{C}$ until further use. All of the steps, including cell collection, soluble extract preparation and the purification procedure, were performed at $4{ }^{\circ} \mathrm{C}$ and $\mathrm{pH}$ 7.6.

\subsection{Extinction Coefficient Determination}

The extinction coefficient was determined by measuring the absorbance at $280 \mathrm{~nm}$ of a pure TupA protein sample quantified using the Bradford method [39] with bovine serum albumin as the standard. The UV-visible absorption spectrum was performed on a Shimadzu UV-2101PC split beam spectrophotometer (Shimadzu, Shimadzu, Japan) using 1-cm optical path quarts cells. The value obtained was in agreement with the one determined using the bioinformatic tool, ProtParam, from the ExPASy portal [29].

\subsection{Protein Gel Shift Assay}

TupA gel shift assays were performed following the protocol described by Rech et al. [8]. Briefly, TupA protein samples $(14 \mu \mathrm{M})$ were incubated with $\mathrm{MoO}_{4}{ }^{2-}, \mathrm{WO}_{4}{ }^{2-}, \mathrm{SO}_{4}{ }^{2-}, \mathrm{PO}_{4}{ }^{3-}$ and $\mathrm{ClO}_{4}{ }^{-}$anions $(140 \mu \mathrm{M})$ in $25 \mathrm{mM}$ Tris- $\mathrm{HCl}(\mathrm{pH} 7.5)$ buffer at room temperature for $25 \mathrm{~min}$. Unbound anions were separated from TupA with a PD10 desalting column (GE Healthcare Bio-Sciences AB, Uppsala, Sweden). Protein samples were mixed with 0.25 volume of sucrose solution $(30 \% \mathrm{w} / \mathrm{v})$ containing bromophenol blue and resolved on a native $12 \%$ polyacrylamide gel buffered with $50 \mathrm{mM}$ Tris- $\mathrm{HCl}$ ( $\mathrm{pH}$ 8.5). The electrophoresis was carried out at $100 \mathrm{~V}, 100 \mathrm{~A}$ and $4{ }^{\circ} \mathrm{C}$ using a $0.1 \mathrm{M}$ Tris- $\mathrm{HCl}$ and $0.1 \mathrm{M}$ glycine ( $\mathrm{pH}$ 8.3) running buffer. The mobility shift assay after anion binding was visualized through the staining of the gel with Coomassie Blue staining solution.

\subsection{Isothermal Titration Calorimetry}

Isothermal titration calorimetry experiments were performed using a VP-ITC calorimeter (MicroCal Inc., GE Healthcare, Pittsbugh, PA, USA). Prior to experiments, protein was dialyzed extensively against the reaction buffer $(5 \mathrm{mM}$ Tris- $\mathrm{HCl}(\mathrm{pH} 7.5))$ made with ultrapure water (Milli Q system, Millipore $\mathrm{AB}$, Sweden). Binding protein $(10 \mu \mathrm{M})$ was equilibrated in reaction buffer at $30{ }^{\circ} \mathrm{C}$ in the cell of the calorimeter, and subsequently, 20 or 23 injections of $10 \mu \mathrm{L}$ of a $100 \mu \mathrm{M}$ sodium tungstate or molybdate solution were performed and the heat response recorded. After subtraction of the baseline, the integrated heat responses were fitted to the single binding site model using the ORIGIN software package (Northampton, MA, USA) supplied with the calorimeter. For competition experiments, the reaction buffer was supplemented with the stated concentrations of molybdate prior to the injections with sodium, tungstate or the reverse. The relationship between apparent binding affinity of the high-affinity ligand $\left(K_{\mathrm{app}}\right)$ and the underlying constants is derived from Equation (1) [40]: 


$$
K_{\text {app }}=\frac{K_{\mathrm{A}}}{\left(1+K_{\mathrm{B}}[\mathrm{B}]\right)}
$$

where $K_{\mathrm{A}}$ is the binding constant for the strong binding ligand and $K_{\mathrm{B}}$ is that for the competitively inhibiting ligand. The apparent binding constant depends on the concentration of the free competitively inhibiting ligand (B) [40].

\subsection{Crystallization}

TupA protein was concentrated up to $7.5 \mathrm{mg} / \mathrm{mL}$ in $5 \mathrm{mM}$ Tris- $\mathrm{HCl}(\mathrm{pH} \mathrm{7.5)}$ with a Vivaspin 20 ultrafiltration device (Sartorius Stedim Biotech S.A., Goettingen, Germany). The final concentration of TupA was determined from the absorbance at $280 \mathrm{~nm}$, using an extinction coefficient of $30,440 \mathrm{M}^{-1} \cdot \mathrm{cm}^{-1}$.

The first crystallization trials were performed at $20{ }^{\circ} \mathrm{C}$ using the sitting-drop vapor diffusion method, with $0.5 \mu \mathrm{L}$ of protein: $0.5 \mu \mathrm{L}$ of precipitant solution on 96-well crystallization plates (SWISSCI 'MRC' 2-Drop Crystallization Plates, Douglas Instruments, Berkshire, UK). Several commercial screens were used, namely the PEG/Ion HT (Hampton Research, Aliso Viejo, CA, USA), the JBScreen Classic 1-10 (Jena Bioscience, Jena, Germany) and an 80 conditions in-house screen (based on the screen of Jancarik et al. [41]). The TupA crystallized in only one of the conditions of the in-house screen containing 0.2 M magnesium chloride, 0.1 M HEPES ( $\mathrm{pH} 7.5)$ and 30\% (w/v) polyethylene glycol 3350. Colorless plate-shaped crystals appeared within 4 days (Figure 6).

Scale-up and optimization experiments were performed, and new crystals with maximum dimensions of $0.3 \times 0.15 \times 0.06 \mathrm{~mm}^{3}$ appeared in hanging-drops with $2 \mu \mathrm{L}$ of protein (at $7.5 \mathrm{mg} / \mathrm{mL}$ ): $1 \mu \mathrm{L}$ of precipitant solution on a 24 -well crystallization plate. These crystals were used to for data collection.

\subsection{Data Collection and Processing}

The crystals were flash-cooled directly in liquid nitrogen, using Paratone as the cryoprotectant, and maintained under a stream of nitrogen gas during data collection.

A complete dataset was collected at beamline ID23-1 at the European Synchrotron Radiation Facility (ESRF, Grenoble, France) and the crystal diffracted up to $1.43 \AA$ at a wavelength of $0.954 \AA$. The TupA crystal belongs to the monoclinic space group, $\mathrm{P} 2{ }_{1}$, with the unit-cell parameters: $a=52.25 \AA, b=42.50 \AA, c=54.71 \AA$ and $\beta=95.43^{\circ}$. The Matthews coefficient was calculated (ca. $2.09 \AA^{3} / \mathrm{Da}$ ) [42], suggesting the presence of one monomer $(\alpha)$ per asymmetric unit, with a solvent content of $40.84 \%$.

Data was processed with the XDS package [43] and AIMLESS [44] from the CCP4 program package v. 6.3.0 (Collaborative Computational Project, Number 4, 1994) [45]. The data collection and processing statistics are presented in the Table 2.

\section{Conclusions}

The transport of tungstate and other analogous oxoanions, like molybdate, is very relevant in organisms that contain key metabolic W/Mo-enzymes, like Desulfovibrio species. Despite this, there are no reports about the characterization of molybdate/tungstate uptake systems from these SRB. 
An analysis of the Desulfovibrio genome annotated to date shows that molybdate and tungstate transporters are encoded in the chromosome of these organisms and belong to the Mod and Tup family of proteins, respectively [1]. Although Mo and W have similar biochemistry [46], molybdate and tungstate transporters can differentiate between them. The molecular basis of the selectivity by the Tup and Mod transporters remains to be understood. Valuable information can be derived from the biochemical and structural characterization of the TupA protein and, particularly, from organisms that contain both (Mod and Tup) kinds of transporters. In this work, we report the expression, purification, preliminary characterization, crystallization and structure determination of DaG20 TupA. In order to attest to the binding of molybdate and tungstate to $D a \mathrm{G} 20$ TupA, gel shift assays were also carried out. Different from the TupA from Eubacterium acidaminophilum [9], DaG20 TupA not only efficiently binds tungstate, but also molybdate anions. In order to quantitatively determine the binding affinity of TupA towards the two oxoanions, isothermal titration calorimetry was carried out. The obtained data show that TupA binds in a 1:1 stoichiometry the two anions, but has much higher affinity to tungstate than to molybdate (around a 1000-times lower $K_{\mathrm{D}}$ value for tungstate anions). Furthermore, in a competitive binding assay, the protein is capable of displacing the molybdate in order to bind what we think is its physiological partner, tungstate. In order to understand the specificity of TupA, site-directed mutagenesis is under way, where some of the putative key residues for binding are going to be inspected.

Conditions to crystallize TupA were found, and the crystals diffract up to $1.43 \AA$. The high resolution structure will allow the detailed characterization of the ligand pocket, coordination geometry and conformational changes upon metal binding, which will help to better understand the mode of action of these transporters.

\section{Acknowledgments}

This work was supported by Fundação para a Ciência e Tecnologia (FCT) (EXPL/BBB-BEP /0274/2012). A.R.O.-C., R.R.N. and M.A.S.C. thank FCT for grants (Reference SFRH/BD/85806/2012, SFRH/BPD/63061/2009 and SFRH/BPD/64917/2009). M.G.R. is a member of the CONICET (Argentina).

The data collection was performed on the ID23-1 beamline at the European Synchrotron Radiation Facility (ESRF), Grenoble, France. We are grateful to local contact Christoph Mueller Dieckmann at ESRF for providing beamline assistance.

We acknowledge Faculdade de Medicina Veterinária da Universidade Técnica de Lisboa for the Isothermal titration calorimetry facility.

\section{Author Contributions}

Ana R. Otrelo-Cardoso and Teresa Santos-Silva performed crystallization, data collection and processing experiments. Rashmi R. Nair and Maria G. Rivas cloned and optimized/purified TupA. Rashmi R. Nair performed TupA preliminary characterization. Márcia A. S. Correia performed ITC experiments and data analysis. All of the authors contributed to the preparation of the manuscript. 


\section{Conflicts of Interest}

The authors declare no conflict of interest.

\section{References}

1. Gonzalez, P.J.; Rivas, M.G.; Mota, C.S.; Brondino, C.D.; Moura, I.; Moura, J.J.G. Periplasmic nitrate reductases and formate dehydrogenases: Biological control of the chemical properties of Mo and $\mathrm{W}$ for fine tuning of reactivity, substrate specificity and metabolic role. Coord. Chem. Rev. 2013, 257, 315-331.

2. Hagen, W.R. Cellular uptake of molybdenum and tungsten. Coord. Chem. Rev. 2011, 255, $1117-1128$.

3. Schwarz, G.; Mendel, R.R.; Ribbe, M.W. Molybdenum cofactors, enzymes and pathways. Nature 2009, 460, 839-847.

4. Grunden, A.M.; Shanmugam, K.T. Molybdate transport and regulation in bacteria. Arch. Microbiol. 1997, 168, 345-354.

5. Maupin-Furlow, J.A.; Rosentel, J.K.; Lee, J.H.; Deppenmeier, U.; Gunsalus, R.P.; Shanmugam, K.T. Genetic analysis of the modABCD (molybdate transport) operon of Escherichia coli. J. Bacteriol. 1995, 177, 4851-4856.

6. Rech, S.; Deppenmeier, U.; Gunsalus, R.P. Regulation of the molybdate transport operon, modABCD, of Escherichia coli in response to molybdate availability. J. Bacteriol. 1995, 177, 1023-1029.

7. Anderson, L.A.; Palmer, T.; Price, N.C.; Bornemann, S.; Boxer, D.H.; Pau, R.N. Characterisation of the molybdenum-responsive ModE regulatory protein and its binding to the promoter region of the modABCD (molybdenum transport) operon of Escherichia coli. Eur. J. Biochem. 1997, 246, 119-126.

8. Rech, S.; Wolin, C.; Gunsalus, R.P. Properties of the periplasmic ModA molybdate-binding protein of Escherichia coli. J. Biol. Chem. 1996, 271, 2557-2562.

9. Makdessi, K.; Andreesen, J.R.; Pich, A. Tungstate uptake by a highly specific ABC transporter in Eubacterium acidaminophilum. J. Biol. Chem. 2001, 276, 24557-24564.

10. Bevers, L.E.; Hagedoorn, P.L.; Krijger, G.C.; Hagen, W.R. Tungsten transport protein A (WtpA) in Pyrococcus furiosus: The first member of a new class of tungstate and molybdate transporters. J. Bacteriol. 2006, 188, 6498-64505.

11. Imperial, J.; Hadi, M.; Amy, N.K. Molybdate binding by ModA, the periplasmic component of the Escherichia coli mod molybdate transport system. Biochim. Biophys. Acta 1998, 1370, 337-346.

12. Smart, J.P.; Cliff, M.J.; Kelly, D.J. A role for tungsten in the biology of Campylobacter jejuni: Tungstate stimulates formate dehydrogenase activity and is transported via an ultra-high affinity ABC system distinct from the molybdate transporter. Mol. Microbiol. 2009, 74, 742-757.

13. Balan, A.; Santacruz, C.P.; Moutran, A.; Ferreira, R.C.; Medrano, F.J.; Perez, C.A.; Ramos, C.H.; Ferreira, L.C. The molybdate-binding protein (ModA) of the plant pathogen Xanthomonas axonopodis pv. citri. Protein Expr. Purif. 2006, 50, 215-222. 
14. Taveirne, M.E.; Sikes, M.L.; Olson, J.W. Molybdenum and tungsten in Campylobacter jejuni: Their physiological role and identification of separate transporters regulated by a single ModE-like protein. Mol. Microbiol. 2009, 74, 758-771.

15. Bevers, L.E.; Schwarz, G.; Hagen, W.R. A molecular basis for tungstate selectivity in prokaryotic ABC transport systems. J. Bacteriol. 2011, 193, 4999-5001.

16. Andreesen, J.R.; Makdessi, K. Tungsten, the surprisingly positively acting heavy metal element for prokaryotes. Ann. N. Y. Acad. Sci. 2008, 1125, 215-229.

17. Hu, Y.; Rech, S.; Gunsalus, R.P.; Rees, D.C. Crystal structure of the molybdate binding protein ModA. Nat. Struct. Biol. 1997, 4, 703-707.

18. Lawson, D.M.; Williams, C.E.; Mitchenall, L.A.; Pau, R.N. Ligand size is a major determinant of specificity in periplasmic oxyanion-binding proteins: The $1.2 \AA$ resolution crystal structure of Azotobacter vinelandii ModA. Structure 1998, 6, 1529-1539.

19. Balan, A.; Santacruz-Perez, C.; Moutran, A.; Ferreira, L.C.; Neshich, G.; Goncalves Barbosa, J.A. Crystallographic structure and substrate-binding interactions of the molybdate-binding protein of the phytopathogen Xanthomonas axonopodis pv. citri. Biochim. Biophys. Acta 2008, 1784, 393-399.

20. Hollenstein, K.; Comellas-Bigler, M.; Bevers, L.E.; Feiters, M.C.; Meyer-Klaucke, W.; Hagedoorn, P.L.; Locher, K.P. Distorted octahedral coordination of tungstate in a subfamily of specific binding proteins. J. Biol. Inorg. Chem. 2009, 14, 663-672.

21. Feio, M.J.; Zinkevich, V.; Beech, I.B.; Llobet-Brossa, E.; Eaton, P.; Schmitt, J.; Guezennec, J. Desulfovibrio alaskensis sp. nov., a sulphate-reducing bacterium from a soured oil reservoir. Int. J. Syst. Evol. Microbiol. 2004, 54, 1747-1752.

22. Lee, W.; Lewandowski, Z.; Nielsen, P.H.; Hamilton, W.A. Role of sulfate-reducing bacteria in corrosion of mild-steel-A review. Biofouling 1995, 8, 165-168.

23. Hamilton, W.A. Microbially influenced corrosion as a model system for the study of metal microbe interactions: A unifying electron transfer hypothesis. Biofouling 2003, 19, 65-76.

24. Sanders, P.F.; Sturman, P.J. Biofouling in the oil industry. In Petroleum Microbiology; Olivier, B., Magot, M., Eds.; American Society for Microbiology: Washington, DC, USA, 2005; pp. 171-198.

25. Peck, H.D. The ATP-dependent reduction of sulfate with hydrogen in extracts of Desulfovibrio desulfuricans. Proc. Natl. Acad. Sci. USA 1959, 45, 701-708.

26. Peck, H.D.J. Enzymatic basis for assimilatory and dissimilatory sulfate reduction. J. Bacteriol. 1961, 82, 933-939.

27. Biswas, K.C.; Woodards, N.A.; Xu, H.; Barton, L.L. Reduction of molybdate by sulfate-reducing bacteria. Biometals 2009, 22, 131-139.

28. Nair, R.R.; Silveira, C.M.; Dinis, M.S.; Almeida, M.G.; Moura, J.J.G.; Rivas, M.G. REQUIMTE/CQFB, Departamento de Química, Faculdade de Ciências e Tecnologia, Universidade Nova de Lisboa, 2829-516 Caparica, Portugal. Unpublished work, 2014.

29. Thompson, J.D.; Gibson, T.J.; Higgins, D.G. Multiple sequence alignment using clustalW and clustalX. In Current Protocols in Bioinformatics; John Wiley \& Sons, Inc.: New York, NY, USA, 2002.

30. Gasteiger, E.; Hoogland, C.; Gattiker, A.; Duvaud, S.; Wilkins, M.R.; Appel, R.D.; Bairoch, A. Protein identification and analysis tools on the ExPASy Server; In The Proteomics Protocols Handbook; Walker, J.M., Ed.; Humana Press: New York, NY, USA, 2005; pp. 571-607. 
31. Padilla, J.E.; Yeates, T.O. A statistic for local intensity differences: Robustness to anisotropy and pseudo-centering and utility for detecting twinning. Acta Crystallogr. D 2003, 59, 1124-1130.

32. McCoy, A.J.; Grosse-Kunstleve, R.W.; Adams, P.D.; Winn, M.D.; Storoni, L.C.; Read, R.J. Phaser crystallographic software. J. Appl. Crystallogr. 2007, 40, 658-674.

33. Postgate, J. Cultivation and Gowth. In The Sulphate-Reducing Bacteria, 2nd ed.; Cambridge University Press: London, UK, 1984; pp. 24-40.

34. Hauser, L.J.; Land, M.L.; Brown, S.D.; Larimer, F.; Keller, K.L.; Rapp-Giles, B.J.; Price, M.N.; Lin, M.; Bruce, D.C.; Detter, J.C.; et al. Complete genome sequence and updated annotation of Desulfovibrio alaskensis G20. J. Bacteriol. 2011, 193, 4268-4269.

35. Wall, J.D.; Rapp-Giles, B.J.; Rousset, M. Characterization of a small plasmid from Desulfovibrio desulfuricans and its use for shuttle vector construction. J. Bacteriol. 1993, 175, 4121-4128.

36. Studier, F.W.; Moffatt, B.A. Use of bacteriophage T7 RNA polymerase to direct selective high-level expression of cloned genes. J. Mol. Biol. 1986, 189, 113-130.

37. Altschul, S.F.; Lipman, D.J. Protein database searches for multiple alignments. Proc. Nat. Acad. Sci. USA 1990, 87, 5509-5513.

38. Thompson, J.D.; Higgins, D.G.; Gibson, T.J. ClustalW: Improving the sensitivity of progressive multiple sequence alignment through sequence weighting, position-specific gap penalties and weight matrix choice. Nucleic Acids Res. 1994, 22, 4673-4680.

39. Bradford, M.M. A rapid and sensitive method for the quantitation of microgram quantities of protein utilizing the principle of protein-dye binding. Anal. Biochem. 1976, 72, 248-254.

40. Velazquez-Campoy, A.; Freire, E. Isothermal titration calorimetry to determine association constants for high-affinity ligands. Nat. Protoc. 2006, 1, 186-191.

41. Jancarik, J.; Kim, S.-H. Sparse matrix sampling: A screening method for crystallization of proteins. J. Appl. Cryst. 1991, 24, 409-411.

42. Matthews, B.W. Solvent content of protein crystals. J. Mol. Biol. 1968, 33, 491-497.

43. Kabsch, W. Xds. Acta Crystallogr. D 2010, 66, 125-132.

44. Evans, P. Scaling and assessment of data quality. Acta Crystallogr. D 2006, 62, 72-82.

45. The CCP4 Suite. Programs for protein crystallography. Acta Crystallogr. D 1994, 50, 760-763.

46. Bevers, L.E.; Hagedoorn, P.-L.; Hagen, W.R. The bioinorganic chemistry of tungsten. Coord. Chem. Rev. 2009, 253, 269-290.

(C) 2014 by the authors; licensee MDPI, Basel, Switzerland. This article is an open access article distributed under the terms and conditions of the Creative Commons Attribution license (http://creativecommons.org/licenses/by/3.0/). 